\section{Identification of microsatellites from an extinct moa species using high- throughput (454) sequence data}

\author{
Morten E. Allentoft ${ }^{1,4}$, Stephan C. Schuster ${ }^{2}$, Richard N. Holdaway1,3, \\ Marie L. Hale ${ }^{1}$, Emma McLay ${ }^{4}$, Charlotte Oskam4, M. Thomas P. \\ Gilbert ${ }^{5}$, Peter Spencer ${ }^{4}$, Eske Willerslev ${ }^{5}$, and Michael Bunce ${ }^{4}$ \\ ISchool of Biological Sciences, University of Canterbury, Christchurch, New \\ Zealand, 2 Pennsylvania State University, Center for Comparative Genomics \\ and Bioinformatics, University Park, PA, USA, ${ }^{3}$ Palaecol Research Ltd, \\ Christchurch, New Zealand, ${ }^{4}$ Ancient DNA laboratory, School of Biological \\ Sciences and Biotechnology, Murdoch University, Perth, Australia, and the \\ sDepartment of Biology, University of Copenhagen, Copenhagen, Denmark
}

BioTechniques 46:195-200 (March 2009) doi 10.2144/000113086

Keywords: ancient DNA; microsatellite development; extinct species; high-throughput 454 sequencing Supplementary material for this article is available at www.BioTechniques.com/article/113086.

Genetic variation in microsatellites is rarely examined in the field of ancient DNA (aDNA) due to the low quantity of nuclear DNA in the fossil record together with the lack of characterized nuclear markers in extinct species. 454 sequencing platforms provide a new high-throughput technology capable of generating up to 1 gigabases per run as short (200-400-bp) read lengths. 454 data were generated from the fossil bone of an extinct New Zealand moa (Aves: Dinornithiformes). We identified numerous short tandem repeat (STR) motifs, and here present the successful isolation and characterization of one polymorphic microsatellite (Moa_MS2). Primers designed to flank this locus amplified all three moa species tested here. The presented method proved to be a fast and efficient way of identifying microsatellite markers in ancient DNA templates and, depending on biomolecule preservation, has the potential of enabling high-resolution population genetic studies of extinct taxa. As sequence read lengths of the 454 platforms and its competitors (e.g., the SOLEXA and SOLiD platforms) increase, this approach will become increasingly powerful in identifying microsatellites in extinct (and extant) organisms, and will afford new opportunities to study past biodiversity and extinction processes.

\section{Introduction}

With theintroduction of newhigh-throughput DNA sequencing techniques capable of generating millions/billions of sequence reads per run, genomic research is advancing faster than ever (1-4). In the field of paleogenetics, the first complete nuclear genome has yet to be recovered, but major sequencing projects of woolly mammoth (5) and Neanderthal (6) are heading what has been called the "third wave" of progress in ancient DNA (aDNA) studies (7). These new sequencing platforms generate large quantities of protein coding data, which will undoubtedly assist in the study of molecular evolution, functional genomics, and adaptation. In addition to coding data, the huge number of randomly amplified sequences provides the opportunity to search for microsatellites or short tandem repeats (STRs). These non-coding sequences with a high rate of mutation are applied as markers in a wide array of genetic research, especially in relation to forensics, modern population biology, and parentage analyses.

A limited number of successful STR amplifications have been reported from ancient substrates using "modern" STRs as templates (8-10) but to our knowledge, no microsatellite primers developed directly from
aDNA templates (let alone extinct species) have been published prior to this study. This is likely due to complications in traditional microsatellite library construction as the result of the degraded and cross-linked nature of ancient DNA (11). Greenwood et al. (10) managed to amplify a single microsatellite locus in woolly mammoth using primers developed for modern elephants. However, to rely solely on primers developed for related modern taxa, when targeting microsatellites in extinct ones, is problematic because of possible low cross-species amplification rates and chance of monomorphism in the target species $(12,13)$. This is especially pertinent in taxa such as moa, where the likelihood of crossspecies amplification is limited as a result of the $>80$ million years that separate moa from their closest living relatives among the ratite birds (14). Consequently, the chance of identifying polymorphic microsatellite markers in ancient DNA templates of an extinct taxon seems greatly enhanced when the potential markers have been identified directly on the target species.

The Roche GS-FLX (454 Life Sciences, Branford, CT, USA) sequencing technology is currently capable of producing 0.1 gigabases per run with a read length averaging 200-300 nucleotides-a sequence size that allows for the presence of an STR and sufficient flanking regions to design primers. A GS-FLX run was conducted on a Pachyornis elephantopus (heavy-footed moa) bone extract to identify a series of microsatellite loci. To illustrate the viability of this technique, we identified an $(\mathrm{AC})_{12}$ microsatellite (directly from raw GS-FLX data) and demonstrated crossspecies amplification in three species of moa. All eleven New Zealand moa species were driven to extinction in the early 15 th century, following the arrival of Polynesians. Identification of new STR markers, such as described here, will enable detailed DNA profiling of extinction processes and past population dynamics of these ancient ratites.

\section{Materials and methods}

Sampling of moa fossils and DNA isolation

Sampling of moa fossils was conducted by drilling out cylindrical elements (diameter of $\sim 1 \mathrm{~cm}$ ) of moa tibiotarsal bones using a power drill and diamonddust coated drill bits. Each sample was then ground into bone powder using a Dremel tool (Part no. 114; Racine, WI, USA). To minimize the incorporation of any possible DNA contamination present on the bones, the bone surfaces and the inner porous parts were excluded, and only solid cortical bone was processed. Contamination from external sources-as well as cross-contami- 
nation between samples-was minimized by thoroughly cleaning equipment and sampling environment (with 10\% bleach and $100 \%$ alcohol) between the processing of each individual. To minimize the risk of a ubiquitous DNA contaminant being present on all the bones, fossils representing three different moa species-from two different sites, and from several different museum/ university collections-were included (Supplementary Table 1). Pyramid Valley and Bell Hill Vineyard Swamp both represent late Holocene deposits in North Canterbury, New Zealand, with a known fossil record spanning app. 3700-700 bp (15, R.N.H. unpublished data).

DNA was extracted from $200 \mathrm{mg}$ of bone powder through incubation with rotation at $55^{\circ} \mathrm{C}$ for $48 \mathrm{~h}$ in $1.5 \mathrm{~mL}$ digestion buffer [20 mM Tris, pH 8.0, 1\% Triton X-100, $10 \mathrm{mM}$ dithiotheitol (DTT), $1 \mathrm{mg} / \mathrm{mL}$ proteinase $\mathrm{K}$ and $0.5 \mathrm{M}$ EDTA]. The supernatant was spun through Centricon 30,000 molecular weight cut-off (MWCO) ultrafiltration devices (Millipore, Billerica, MA, USA) columns combined with 5 volumes of PBI buffer (Qiagen, Valencia, CA, USA) and DNA was then extracted using silica spin columns (Qiagen) and cleaned with AW1 and AW2 wash buffers (Qiagen) before final elution in $60 \mu \mathrm{l}$ of $10 \mathrm{mM}$ Tris buffer. For species identification, and to confirm the relative quantities of aDNA in the fossil extracts, a 242-bp sequence of moa mitochondrial control region was amplified (by qPCR) using the species-specific primer set 262f/441r (Supplementary Figure 3) and then sequenced as described in Bunce et al. (16) (data not shown).

GS-FLX sequencing, microsatellite primer development and PCR

ADNA extract from a single moa individual (P. elephantopus) from the Bell Hill Vineyard Swamp, which demonstrated good qPCR amplification and long nuclear amplicons (data not shown), was picked for a quarterplate run on a GS-FLX instrument (Center for Comparative Genomics and Bioinformatics, Pennsylvania State University, PA, USA). The moa DNA library was constructed, as previously described $(5,17)$, with the modification of leaving the extracted DNA unsheared before blunt-ending and phosphorylating the DNA fragments by enzymatic polishing using T4 DNA polymerase, T4 polynucleotide kinase, and E. coli DNA polymerase. The blunt-ended, double stranded DNA fragments were then subjected to adapter ligation followed by isolation of the single-stranded template DNA (sstDNA). Subsequently, DNA library fragments were captured onto beads and clonally amplified within individual

A

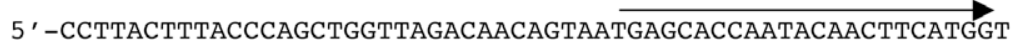

TATGCAATATGCATGGAATATATGT ACACACACACACACACACACACACATACATATATA

AACAAACATATACTGGAATAGAATAACAGTCTCAAAGAAAA-3 '
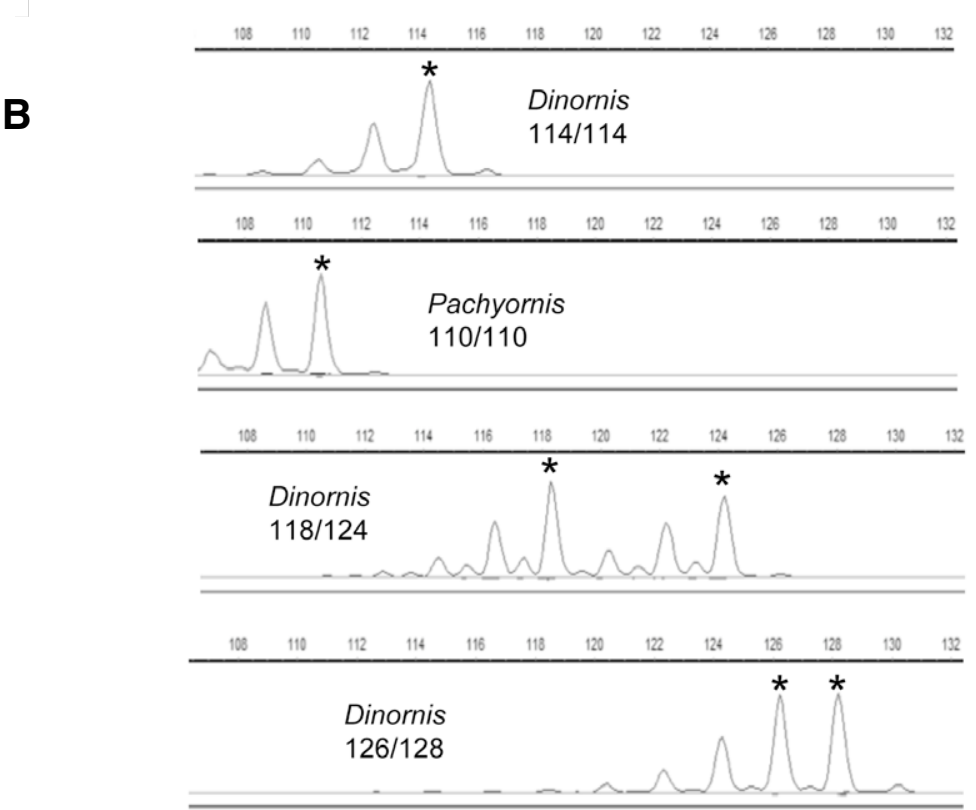

Figure 1. Identification of a polymorphic microsatellite (Moa_MS2) in an extinct species. (A) The orginal clone identified in the GS-FLX data (clone \# 103234_2765_0456). The $(A C)_{12}$ repetitive region is boxed and the location of forward and reverse primer sequences indicated by arrows. (B) Chromatographs obtained from the amplification of the Moa_MS2 locus in two moa genera (Dinornis and Pachyornis). Modified screencapture from GENEMARKER version 1.5. The upper two panels show homozygotes and the two lower panels show heterozygotes. Alleles are marked with an asterisk and aditional peaks represent stutter and A+ peaks, commonly observed during STR profiling. Chromatographs from other species/individuals are found in Supplementary Figure 1.

emulsion droplets (emPCR). The emulsions were disrupted using isopropanol and beads containing amplified DNA fragments were enriched and recovered for sequencing. The recovered sstDNA beads were packed onto a quarter division of a $70 \mathrm{~mm} \times 75 \mathrm{~mm}$ PicoTiterPlate (454 Life Sciences) and loaded onto the GS-FLX sequencing system as previously described (5). The sequencing run yielded 79,796 sequences averaging $112 \mathrm{bp}$ in length. Subsequently, the data were screened for STR sequences using MSATCOMMANDER (18) and a total of 195 di-, tri-, and tetranucleotide repeat sequences were detected (23 of them with six or more repeats). Seven of these proved particularly promising, with flanking regions of sufficient lengths and a base composition suitable for primer design (Figure 1A and Supplementary Figure 2). The sequence chosen for initial trial was clone \# 1032342765 0456, a 158-bp sequence which included an (AC) 12 dinucleotide repeat (Figure 1A, GenBank accession no. FJ513189). Primers were then manually designed from this original clone to target a 114-bp sequence, designated Moa_MS2 (Figure 1A).

Each microsatellite PCR was conducted in a $25-\mu \mathrm{L}$ volume containing $2 \mu \mathrm{L}$ DNA extract, $1 \mu \mathrm{L} 10 \mathrm{mg} / \mathrm{mL}$ bovine serum albumin (BSA), $1 \mu \mathrm{L}$ each of $10 \mathrm{mM}$ forward (5'-TGAGCACCAATACAACTTCATGG-3') and reverse primer (5'-GACTGTTATTCTATTCCAGTATATGTTTG-3'), 2.5 uL 10× ABI Gold Buffer, $2.5 \mu \mathrm{L} 25 \mathrm{mM} \mathrm{MgCl}_{2}, 0.2 \mu \mathrm{L} 5$ units/ $\mu \mathrm{A}$ ABI Gold Taq polymerase, $0.25 \mu \mathrm{L}$ of each dNTP $(25 \mathrm{mM})$ and $14.55 \mu l$ ultrapure $\mathrm{H}_{2} \mathrm{O}$ (Catalog nos. 4311816 and AM 9935; Applied Biosystems, Foster City, CA, USA). Thermal cycling was initiated with a $3-\mathrm{min}$ $95^{\circ}$ denaturation step followed by 50 cycles of $95^{\circ}$ for $20 \mathrm{~s}, 57^{\circ}$ for $45 \mathrm{~s}$, and $72^{\circ}$ for $45 \mathrm{~s}$. A final extension was carried out at $72^{\circ}$ for $10 \mathrm{~min}$ to maximize adenylation. Negative extraction and amplification controls were always included. DNA fragments were separated on an ABI 3730 genetic analyzer and sized by co-running a Genescan LIZ500 size standard (Applied Biosystems, Foster 
Table 1. Summary Statistics for the Moa_MS2 Microsatellite Locus

\begin{tabular}{|c|c|c|c|c|c|c|c|}
\hline \multirow[b]{2}{*}{ Species } & \multirow[b]{2}{*}{ Size range (bp) } & \multirow[b]{2}{*}{$\mathbf{n}$} & \multirow[b]{2}{*}{$N_{\mathrm{A}}$} & \multirow[b]{2}{*}{$N_{\mathrm{E}}$} & \multirow[b]{2}{*}{$F_{\text {IS }}$} & \multicolumn{2}{|c|}{ Heterozygosity } \\
\hline & & & & & & $H_{0}$ & $\boldsymbol{H}_{\mathrm{E}}$ \\
\hline South Island giant moa (D. robustus) & $110-136$ & 31 & 10 & 3.1 & 0.143 & 0.581 & $0.677 \pm 0.089$ \\
\hline Stout legged moa (E. gravis) & $110-128$ & 11 & 8 & 5.8 & 0.230 & 0.636 & $0.826 \pm 0.145$ \\
\hline Heavy footed moa ( $P$. elephantopus) & $106-110$ & 10 & 2 & 1.9 & 0.167 & 0.400 & $0.505 \pm 0.155$ \\
\hline
\end{tabular}

City, CA, USA).DNA fragments were scored manually with the aid of GENEMARKER version 1.5 (Soft Genetics, State College, PA, USA). To check the integrity of the microsatellite, several individual Moa_MS2 amplification products were cloned using a TOPO TA cloning kit (Invitrogen, Carlsbad, CA, USA) and sequenced using vector specific M13 primers according to the manufacturer's instructions. Comparisons of the clone sequence data with the original GS-FLX clone confirmed that the Moa_MS2 locus was amplified (data not shown). In accordance with aDNA guidelines, DNA extractions and PCR setup occurred in separate and dedicated aDNA facilities at Murdoch University (Perth, Australia).

\section{Results and discussion}

Of the 74 bone DNA extracts prescreened with mtDNA control region amplifications, 52 amplified with the Moa_MS2 primers. The generated chromatographs were consistent with expected dinucleotide STR patterns (including stutters and $\mathrm{A}+$ peaks, see Figure $1 \mathrm{~B}$ and Supplementary Figure 1). The Moa_MS2 locus yielded a total of 13 different alleles in the three extinct moa genera tested here (Dinornis, Pachyornis, and Euryapteryx). Summary statistics for this single locus are presented in Table 1. Because of the relatively low quality of the template molecules in the fossils, some alleles did not always amplify with the same efficacy in heterozygotes, and allele dropout was observed on occasion. This is not totally unexpected for microsatellites in ancient or low copy number substrates (19), and when this marker is applied in actual population research (M.A., R.N.H., and M.B., unpublished data), these issues would need to be accounted for through multiple replicates and established protocols $(20,21)$. The chromatographs shown in Figure 1B are a sample of profiles (two homozygotes and two heterozygotes) obtained from 4 moa fossils and demonstrate the 2-bp stuttering characteristic of dinucleotide STR in addition to A+ peaks. Other chromatographs can be found in the supplementary information (Supplementary Figure 1).

The developed primer set amplified across all the three moa genera tested, and-more importantly-displayed polymorphism (Table 1), making it ideal for population studies. Attempts to amplify the Moa_MS2
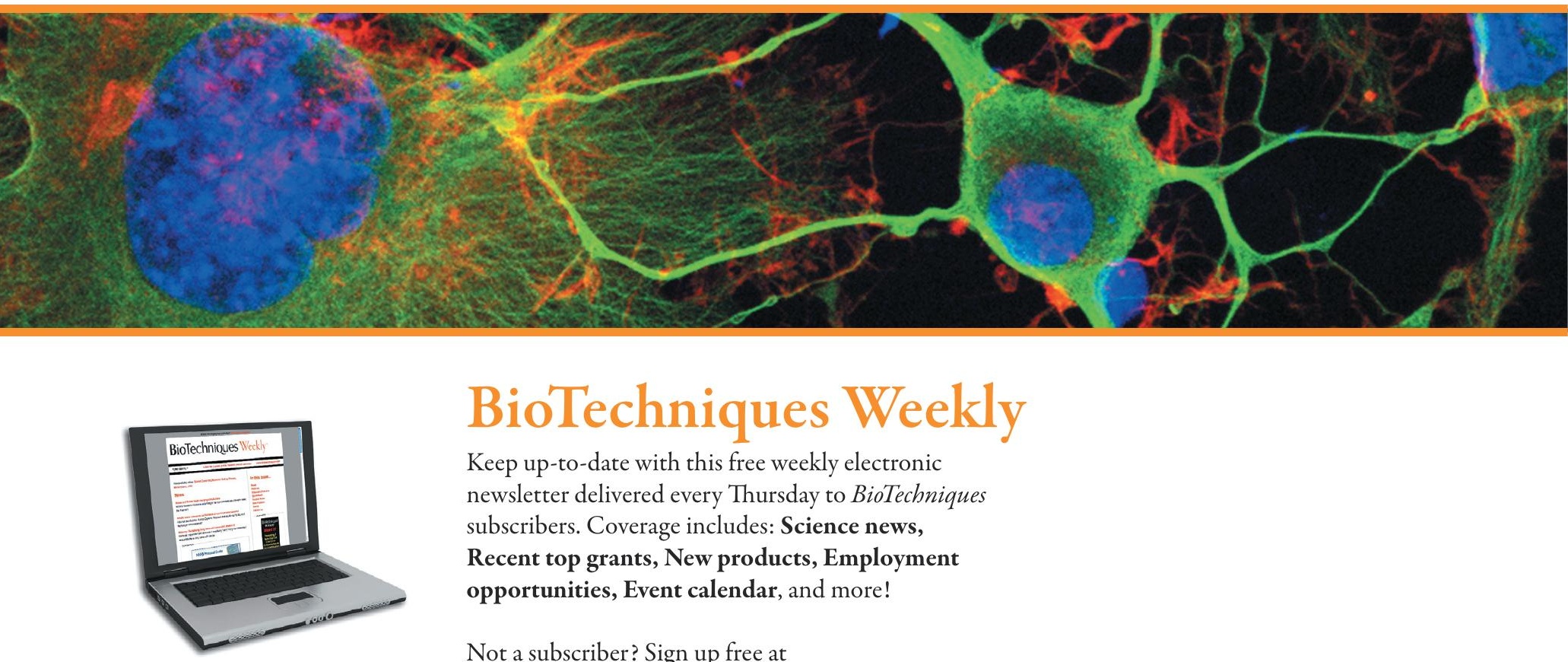

\section{Bio'Techniques Weekly}

Keep up-to-date with this free weekly electronic newsletter delivered every Thursday to BioTechniques subscribers. Coverage includes: Science news, Recent top grants, New products, Employment opportunities, Event calendar, and more!

Not a subscriber? Sign up free at www.BioTechniques.com/newsletters 
locus in other ratites (emu, ostrich, rhea) were unsuccessful but considering the deep split to the most recent common ancestor, this was not unexpected. Since this study serves to document the use of high-throughput sequence data as a source of microsatellites, a further characterization of the allelic diversity in relation to the various moa species is beyond the scope of this proof-ofconcept paper. Clearly, population genetic analyses based on microsatellite data require multiple polymorphic loci. Significantly, our results demonstrate how several potential markers were identified in this quarter-plate GS-FLX run. Although only one STR has been evaluated here, at least seven STRs appeared potentially suitable as genetic markers (Figure S2). Given that birds exhibit a relatively low frequency of microsatellites (22), the frequency of detected microsatellites per run may be even greater in other vertebrate lineages. We screened $\sim 64,000$ clones of GenBank mammoth data (5), generated using the GS-20 sequencing platform (454 Life Sciences), for microsatellites and identified 15 STRs with $\geq 6$ repeating units (data not shown). The shorter read lengths of the GS-20 ( $100 \mathrm{bp}$ ), used in the mammoth study, likely explain the slightly lower frequency of identified microsatellites
(0.023\%) when compared with the GS-FLX ( 200bp) moa run (0.029\%).

The characterization of DNA from the fossil record is not without challenges. In fossil bones recovered from soil, a fraction of the present biomolecules is likely to be of bacterial or fungal origin, see $(5,23)$. Moreover, museum specimens are commonly contaminated with human DNA from previous handling (24). When using shotgun sequencing methods such as the ones described here, all DNA molecules in an extract are amplified with equal chance (however, see Reference 25), including any exogenous DNA. Hence, in theory, there is a potential risk of identifying microsatellitesand even conduct population analyses-for the microbial flora/fauna or other contaminants associated with the fossils instead of the target species itself. With regard to the data presented here, we consider human contamination unlikely because the flanking regions of Moa_MS2 demonstrated no significant matches when queried against the human genome database. The paucity of environmental microbe sequences in GenBank makes a similar approach to detect microbes more problematic, but in the case of Moa_MS2, it is unlikely to be of microbial origin for the following reasons: (i) Though present, microsatellites are much scarcer in prokaryotes and fungus compared with higher eukaryotes (26-29). (ii) Many heterozygotes were detected among the 52 genotyped moa, whereas the haploid nature of bacteria should generate only one allele per clone. (iii) Fungi exist in a variety of ploidy states, and we never observed more than 2 alleles in any of the fossil bone profiles. (iv) Fossils from different collections and originating from very different depositional environments in New Zealand with different microbial communities still yielded reproducible amplifications. $(v)$ Allele frequencies differed among species (see Supplementary Table 2); for example, alleles 106, 114, and 124 are considered "private" alleles for Pachyornis, Dinornis, and Euryapteryx respectively. These findings are incompatible with the possibility that the locus is not of moa origin. (vi) Lastly, the qPCR data presented in Supplementary Figure 3 show a significant difference $(t$-test, $P=0.000038)$ between mean mtDNA control-region $C t$ values for those DNA extracts that yielded a Moa MS2 profile (mean $\mathrm{Ct}=32.4$ ) and those that yielded mtDNA but failed to amplify the Moa_MS2 locus (mean Ct $=36.7)$. Fossils with poor mtDNA preservation (high $\mathrm{Ct}$ values) had a lower success rate for amplifi-

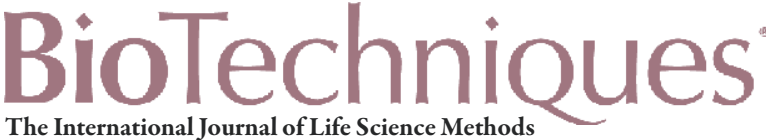

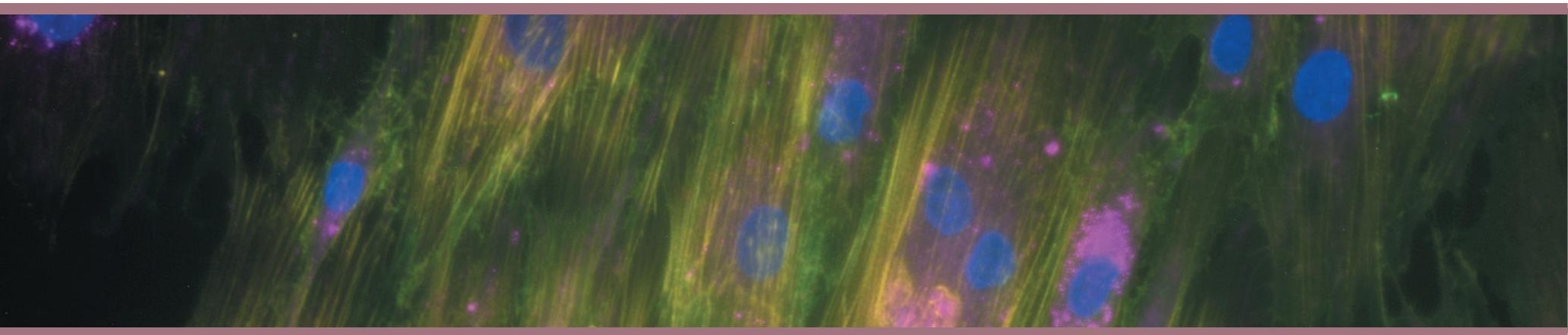

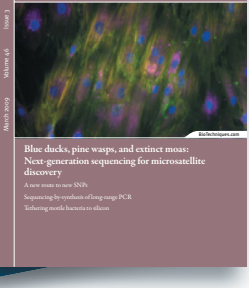

\section{Free Subscription}

BioTechniques is the first peer-reviewed journal with

open access to the whole of the life science community.

$100 \%$ life science

$100 \%$ peer-reviewed methods

$100 \%$ "everyday" practical information

Sign up for free at

www.BioTechniques.com/subscribe 
cation of the nuclear marker. A quantitative correlation, such as observed here, should not exist if the microsatellite originated from a source other than moa.

In summary, data generated using a highthroughput DNA sequencing technique were pivotal in identifying a polymorphic microsatellite marker in the extinct New Zealand moa. Mining genomic data for microsatellites is especially relevant to aDNA where the preservation is not conducive to more traditional approaches of library enrichment and construction. We argue that STRs identified using shotgun sequencing approaches, coupled with better DNA isolation techniques, will facilitate research into high-resolution ancient population genetics similar to those currently conducted on extant species.

As average 454 read lengths increase to $\sim 400 \mathrm{bp}$ (30) and the costs of sequencing decrease, the number of potential microsatellite markers identified per run can increase dramatically. It may not be long before shotgun sequencing will replace traditional enrichment library approaches, with one major benefit being the large amount of ancillary mitochondrial and nuclear data that are generated. Moreover, when enrichments steps are combined with coded primers (31), it will be possible to generate microsatellite libraries from multiple species simultaneously. In the context of aDNA, the use of enrichment steps may present a number of additional technical challenges (such as the extent of cross linking) and may be dependent on DNA preservation within the substrate.

\section{Acknowledgements}

We would like to gratefully acknowledge the following institutions for samples: Museum of New Zealand Te Papa Tongarewa (A.J.D. Tennyson), Canterbury Museum (P. Scofield) and The American Museum of Natural History. We thank Malene Møhl, Fiona Wilson, James Haile, and Ross Barnett for help during the bone sampling process and Lynn Tomsho for technical assistance in the GS-FLX sequencing. Financial support was provided by The Australian Research Council (DP0771971) and the Marsden Fund of the Royal Society of New Zealand (programme 06-PAL-001-EEB) with Palaecol Research, Ltd. Stephan C. Schuster is supported in part by the Gordon and Betty Moore Foundation.

The authors declare no competing interests.

\section{References}

1. Mardis, E.R. 2008. The impact of next-generation sequencing technology on genetics. Trends Genet. 24:133-141.
2. Medini, D., D. Serruto, J. Parkhill, D.A. Relman, C. Donati, R. Moxon, S. Falkow, and R. Rappuoli. 2008. Microbiology in the post-genomic era. Nat. Rev. Microbiol. 6:419-430.

3. Blow, N. 2008. DNA sequencing: generation next-next. Nat. Methods 5:267-274.

4. Schuster, S.C. 2008. Next-generation sequencing transforms today's biology. Nat. Methods 5:16-18.

5. Poinar, H.N., C. Schwarz, J. Qi, B. Shapiro, R.D.E. MacPhee, B. Buigues, A. Tikhonov, D.H. Huson, et al. 2006. Metagenomics to paleogenomics: Large-scale sequencing of mammoth DNA. Science 311:392-394.

6. Green, R.E., J. Krause, S.E. Ptak, A.W. Briggs, M.T. Ronan, J.F. Simons, L. Du, M. Egholm, et al. 2006. Analysis of one million base pairs of Neanderthal DNA. Nature 444:330-336.

7. Millar, C.D., L. Huynen, S. Subramanian, E. Mohandesan, and D.M. Lambert. 2008. New developments in ancient genomics. Trends Ecol. Evol. 23:386-393.

8. Amory, S., C. Keyser, E. Crubezy, and B. Ludes. 2007. STR typing of ancient DNA extracted from hair shafts of Siberian mummies. Forensic Sci. Int. 166:218-229.

9. Manen, J.F., L. Bouby, O. Dalnoki, P. Marinval, M. Turgay, and A. Schlumbaum. 2003. Microsatellites from archaeological Vitis vinifera seeds allow a tentative assignment of the geographical origin of ancient cultivars. J. Archaeol. Sci. 30:721729.

10. Greenwood, A.D., F. Lee, C. Capelli, R. DeSalle, A. Tikhonov, P.A. Marx, and R.D.E. MacPhee. 2001. Evolution of endogenous retrovirus-like elements of the woolly mammoth (Mammuthus primigenius) and its relatives. Mol. Biol. Evol. 18:840-847.

11. Paabo, S. 1989. Ancient DNA: extraction, characterization, molecular cloning, and enzymatic amplification. Proc. Natl. Acad. Sci. USA 86:19391943.

12. Primmer, C.R., A.P. Moller, and H. Ellegren. 1996. A wide-range survey of crossspecies microsatellite amplification in birds. Mol. Ecol. 5:365-378.

13. Primmer, C.R., J.N. Painter, M.T. Koskinen, J.U. Palo, and J. Merila. 2005. Factors affecting avian cross-species microsatellite amplification. J. Avian Biol. 36:348-360.

14. Cooper, A., C. Lalueza-Fox, S. Anderson, A. Rambaut, J. Austin, and R. Ward. 2001. Complete mitochondrial genome sequences of two extinct moas clarify ratite evolution. Nature 409:704707.

15. Burrows, C.J. 1989. Moa browsing: evidence from the Pyramid Valley mire. N. Z. J. Ecol. 12:51-56.

16. Bunce, M., T.H. Worthy, T. Ford, W. Hoppitt, E. Willerslev, A. Drummond, and A. Cooper. 2003. Extreme reversed sexual size dimorphism in the extinct New Zealand moa Dinornis. Nature 425:172-175.

17. Margulies, M., M.Egholm, W.Altman, S. Attiya, J. Bader, L. Bemben, J. Berka, et al. 2005. Genome sequencing in microfabricated high-density picolitre reactors. Nature 437:376-380.

18. Faircloth, B.C. 2008. MSATCOMMANDER: detection of microsatellite repeat arrays and automated, locus-specific primer design. Mol. Ecol. Resour. 8:92-94.

19. Burger, J., S. Hummel, B. Herrmann, and W. Henke. 1999. DNA preservation: A microsatellite-DNA study on ancient skeletal remains. Electrophoresis 20:1722-1728.
20. Taberlet, P., S. Griffin, B. Goossens, S. Questiau, V. Manceau, N. Escaravage, L.P. Waits, and J. Bouvet. 1996. Reliable genotyping of samples with very low DNA quantities using PCR. Nucleic Acids Res. 24:3189-3194.

21. Morin, P.A., K.E. Chambers, C. Boesch, and L. Vigilant. 2001. Quantitative polymerase chain reaction analysis of DNA from noninvasive samples for accurate microsatellite genotyping of wild chimpanzees (Pan troglodytes verus). Mol. Ecol. 10:1835-1844

22.Primmer, C.R., T. Raudsepp, B.P. Chowdhary, A.R. Moller, and H. Ellegren. 1997. Low frequency of microsatellites in the avian genome. Genome Res. 7:471-482.

23. Noonan, J.P., M. Hofreiter, D. Smith, J.R. Priest, N. Rohland, G. Rabeder, J. Krause, J.C. Detter, et al. 2005. Genomic sequencing of Pleistocene cave bears. Science 309:597-600.

24.Gilbert, M.T.P., L. Rudbeck, E. Willerslev, A.J. Hansen, C. Smith, K.E.H Penkman, K. Prangenberg, C.M.Nielsen-Marsh et al. 2005. Biochemical and physical correlates of DNA contamination in archaeological human bones and teeth excavated at Matera, Italy. J. Archaeol. Sci. 32:785-793.

25. Dohm, J.C., C. Lottaz, T. Borodina, and H. Himmelbauer. 2008. Substantial biases in ultrashort read data sets from high-throughput DNA sequencing. Nucleic Acids Res. 36:e105.

26. Karaoglu, H., C.M.Y. Lee, and W. Meyer. 2005. Survey of simple sequence repeats in completed fungal genomes. Mol. Biol. Evol. 22:639-649.

27. Toth, G., Z. Gaspari, and J. Jurka. 2000. Microsatellites in different eukaryotic genomes: Survey and analysis. Genome Res. 10:967-981.

28. Schlotterer, C., M. Imhof, H. Wang, V. Nolte, and B. Harr. 2006. Low abundance of Escherichia coli microsatellites is associated with an extremely low mutation rate.J. Evol. Biol. 19:16711676.

29. Field, D. and C. Wills. 1998. Abundant microsatellite polymorphism in Saccharomyces cerevisiae, and the different distributions of microsatellites in eight prokaryotes and $S$. cerevisiae, result from strong mutation pressures and a variety of selective forces. Proc. Natl. Acad. Sci. USA 95:1647-1652.

30. Droege, M. and B. Hill. 2008. The Genome Sequencer FLX System-longer reads, more applications, straight forward bioinformatics and more complete data sets. J. Biotechnol. 136:3-10.

31. Binladen, J., M.T.P. Gilbert, J.P. Bollback, F. Panitz, C. Bendixen, R. Nielsen, and E. Willerslev. 2007. The use of coded PCR primers enables high-throughput sequencing of multiple homolog amplification products by 454 parallel sequencing. PLoS ONE 2:e197.

Received 15 September 2008; accepted 16 December 2008.

Address correspondence to Michael Bunce, School of Biological Sciences and Biotechnology, Murdoch University, Perth 6150,Australia.email:m.bunce@ murdoch.edu.au 